\title{
LESSON 87
}

MARGINS: Pica, 20-70; Elite, 30-80.

\section{Increase Speed}

35 wpm 5 minutes.

$\mathrm{S} 36-\mathrm{SI} 1.08$

\section{Improve Accuracy}

30 wpm 5 minutes.

A32 - SI 1.20

Memo 3

PAPER: A5 $(210 \times 148 \mathrm{~mm})$.

TARGET TIME: 10 minutes.

Take one carbon copy.

\section{UNIT 22}

The mention of home-made drinks such as wine,

beer or mead, can be the start of as many tales as the ear can stand. Those who do not know much can tell tales of the great strength of the drinks and do not pay regard to the truth. It is not that he or she tells lies but they tend to stretch a point now and then.

A true home wine or beer maker will know what truth there is in tales of the strength of a drink and may dream, as the tale goes on. They may well know that the tale was born, when the thought of a free drink or two in the warmth of a home soon led to the teller having far more to drink than it was the custom for him to have, with the result that a day or so would pass, before he gained his fullest senses again.

Some home-made drinks are strong but the wise know it is best to make them less strong than some beginner who has heard the tales. They need a lot of strong nerve to drink a strong wine.

There are many ways in which any young typist can improve her ability as a typist. The first is to read through any work to be typed and to try as far as is possible to see the problems to be faced in that job.

If you can see that a piece of work will only just fit the typing page and you fear that you may find the paper has come out of the machine towards the end of the job, draw a thick black line on the backing sheet roughly an inch from the bottom. As you come to the bottom of the paper you are typing on you will see the line and know that you must be careful.

Keep a check on your errors and try to see if there is a pattern. If there is, look up the page of the corrective drill in this book and type what it suggests. Make sure the error is not caused by fatigue.

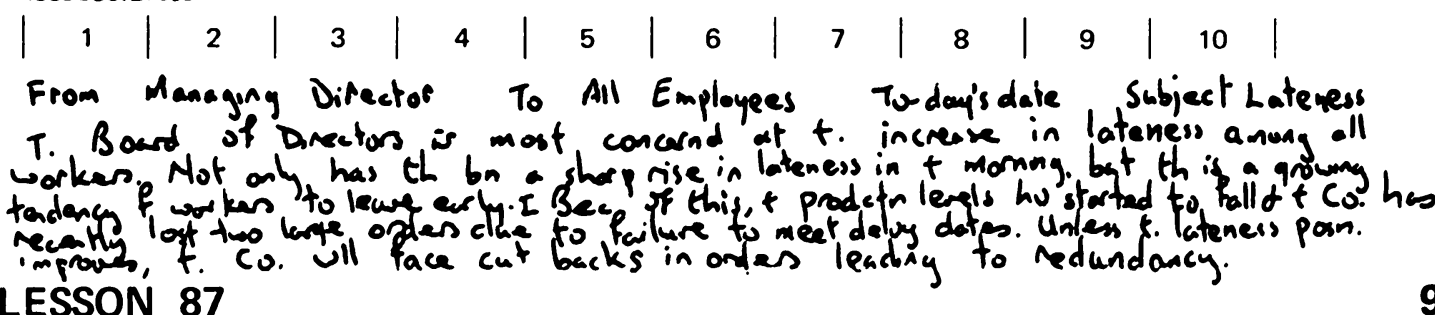

